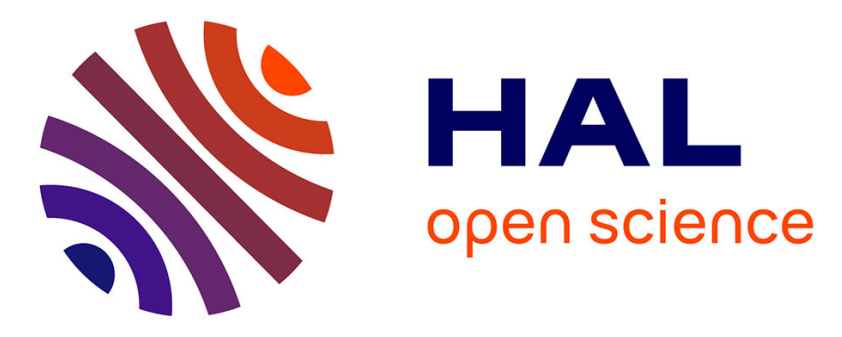

\title{
Investigating the impact behaviour of short hemp fibres reinforced polypropylene biocomposites through high speed imaging and finite element modelling
}

Laurent Puech, Karthik Ram Ramakrishnan, Nicolas Le Moigne, Stéphane Corn, Pierre Slangen, Anne Le Duc, Hassane Boudhani, Anne Bergeret

\section{To cite this version:}

Laurent Puech, Karthik Ram Ramakrishnan, Nicolas Le Moigne, Stéphane Corn, Pierre Slangen, et al.. Investigating the impact behaviour of short hemp fibres reinforced polypropylene biocomposites through high speed imaging and finite element modelling. Composites Part A: Applied Science and Manufacturing, 2018, 109, pp.428-439. 10.1016/j.compositesa.2018.03.013 . hal-02012087

\section{HAL Id: hal-02012087 \\ https://hal.science/hal-02012087}

Submitted on 18 Mar 2019

HAL is a multi-disciplinary open access archive for the deposit and dissemination of scientific research documents, whether they are published or not. The documents may come from teaching and research institutions in France or abroad, or from public or private research centers.
L'archive ouverte pluridisciplinaire HAL, est destinée au dépôt et à la diffusion de documents scientifiques de niveau recherche, publiés ou non, émanant des établissements d'enseignement et de recherche français ou étrangers, des laboratoires publics ou privés. 


\section{Investigating the impact behaviour of short hemp fibres reinforced polypropylene biocomposites through high speed imaging and finite element modelling}

Laurent Puech ${ }^{1,3}$, Karthik Ram Ramakrishnan ${ }^{1, b_{*},}$, Nicolas Le Moigne ${ }^{1}$, Stéphane Corn ${ }^{1 * *}$, Pierre R. Slangen ${ }^{2}$, Anne Le Duc ${ }^{3}$, Hassane Boudhani ${ }^{4}$, Anne Bergeret ${ }^{1}$

${ }^{1}$ C2MA, IMT Mines Ales, Université de Montpellier, 6 avenue de Clavières, 30319 Ales Cedex, France ${ }^{a}$

${ }^{2}$ Institute for Risk Sciences, LGEI, Ecole des Mines d'Alès, 6 avenue de Clavières, 30319 Alès Cedex, France

${ }^{3}$ Fibres Recherche Développement (FRD), Technopole de l'Aube en Champagne, Hôtel des Bureaux 2, 2 rue Gustave Eiffel, CS 90601, 10901 Troyes Cedex 9, France

${ }^{4}$ Faurecia Interior Systems (FIS), 8 Rue Emile Zola, 60114 Méru, France

${ }^{a}$ C2MA is member of the European Polysaccharide Network of Excellence (EPNOE), http://www.epnoe.eu.

${ }^{b}$ Current address: Materials Science Laboratory, Tampere University of Technology, Tampere 33101,

Finland

Corresponding authors: *Karthik Ram Ramakrishnan (karthik.ramakrishnan@tut.fi); **Stéphane Corn (stephane.corn@mines-ales.fr) 


\begin{abstract}
In several industrial sectors, structural composite materials with good impact resistance are required to design parts submitted to crashes or falling objects. This work analyses the impact behaviour of short hemp fibres reinforced biocomposites through mechanical measurements, high speed imaging and finite element modelling. A drop-weight impact machine was instrumented with a high speed camera to measure the propagation of macro-cracks and correlate it to the force-displacement dynamic response at several impact energy levels. PP-hemp composites exhibit higher absorbed energies (up to 40\%) than PP-glass composites due to higher strain at break. The video tracking analysis highlights that for a given cumulated crack length, PP-hemp composite absorbs much more energy, related to differences in failure mechanisms. The developed finite element model is in good agreement with the experimental measurements and the fracture growth pattern, thus constituting a useful tool to predict the impact response of biocomposite parts.
\end{abstract}

Keywords: A. Biocomposite ; B. Impact behaviour ; C. Finite element analysis (FEA); D. Mechanical testing; (Additional keyword: High speed imaging) 


\section{Introduction}

The use of natural fibres as reinforcements for polymer composites has gradually increased in recent years mainly because of two environmental assets: their low energy demand for production and their renewability [1]. Moreover, natural fibres present interesting physical properties when compared to manmade reinforcement fibres such as glass fibres: their low density leads to highly competitive specific mechanical properties in addition to good viscoelastic damping performances [2-4]. These properties make natural fibres good substitutes to glass fibres in many industrial applications. For instance, automotive specifications require materials with good impact properties as the parts designed are usually subjected to damages caused by bumps, crashes or falling objects. It is difficult to assess the impact resistance of composites due to the complex damage modes related to the bulk and interfacial properties of matrix and fibres that lead to matrix failure, fibre breakage and fibre pull-out. Thus the analysis of failure mechanisms in composites subjected to impact is of major interest.

Several authors compared the impact behaviour of natural fibre reinforced composites to traditional glass fibre ones [5-12]. Among them, Patel et al.[5], Scarponi et al. [6], and Santulli et al. [7-9] showed that for glass fibre reinforced epoxy and polyester resins, peak loads and absorbed energies at breakage were higher than those of hemp fibre reinforced composites, but the latter exhibited a higher strain at break. Santulli et al. [7-9] postulated that the difference in absorbed energy between natural fibres (jute, flax and hemp) and glass reinforced epoxy composites was due to a shorter elastic phase upon impact loading in the case of biocomposites leading to lower peak loads as compared to glass fibre reinforced composites. These authors also found out that unlike the glass reinforced composites, the loading phase of the biocomposites is slightly curved which means it suffered internal damage, although it could not be seen at the surface. In those materials, failure was mainly driven by matrix cracking and the sample does not undergo penetration until a large amount of matrix cracking takes place and leads to fibre breakage and pull-out which occur at higher absorbed energy. Biocomposites could thus exhibit a good penetration resistance even after damage initiation. Besides, Patel et al.[5] also found that for low fibre volume fraction $(<20$ vol\%), the differences in absorbed energy between glass and natural fibres composites were not significant. Caprino et al.[10-12] pointed out that epoxy-hemp biocomposites needed higher impact energy to initiate damage when compared to epoxy-glass composites. This result suggests that natural fibre composites can have comparable impact 
damage tolerance as glass fibre composites. Moreover, an interface treatment such as alkaline, silane or a combination of both could even increase the energy absorbed by the biocomposites upon impact [5]. Most of the studies dealing with impact behaviour of natural fibres reinforced composites were mainly based on uniaxial impact tests such as Izod or Charpy tests $[13,14]$. There is limited literature dealing with biaxial impact tests of natural fibre composites performed on drop-weight impact machine. Moreover, if low velocity impact tests were conducted on such composites $[15,16]$, very few authors tried to correlate their impact behaviour to crack propagation. Nevertheless, some works attempted to correlate the impact energy to the damaged area, i.e. in the case of long fibre composite the delamination area, but the analyses were only based on post-mortem observations and not on the tracking of crack propagation during the impact test $[6,12,17,18]$.

The numerical simulation of the response of composite structures to impact loads is of particular interest for automotive applications related to passenger and pedestrian safety as these materials are increasingly being used in critical applications and structures [19]. The numerical modelling of fibre reinforced polymer composites is possible at different scales: micro, meso and macro-scale [20]. Sliseris et al. [21] described the microstructural characteristics of short flax fibre and flax fabric in their numerical model and demonstrated that the simulation was able to capture the main damage mechanisms of the composite. Some researchers [22,23] determined the anisotropic and locally varying effective elastic properties of short fibre reinforced plastics using the elastic properties of the fibre and the matrix and a homogenisation algorithm that mapped the orientation distribution of the fibres. Nutini and Vitali [24] recommended using an anisotropic, non-linear and strain-rate dependent material law that already exists in the library of commercial Finite Element (FE) codes and obtained useful and reliable results with limited computational cost for a range of benchmark problems. Chethan et al. [25] recommended that a more viable tool for analysing industrial components was a macro-mechanical modelling approach based on the experimental non-linear stress-strain behaviour of the composites up to breakage. Isotropic models that neglect the microstructural features and the directional dependency of the material properties and instead use preferential flow direction properties were still able to provide designers with predictive knowledge of the problem. Sandberg and Rydholm [26] investigated the impact response during two complex load cases, and compared the results of a simple elasto-plastic material law and failure model with a more complex crash model and showed that the elasto-plastic model gave similar material behaviour prediction and had the 
potential to reduce simulation time. Hosseinzadeh et al. [27] reported that a macroscopic model is capable of predicting the threshold of damage, which is a good design criterion for composites. Chethan et al. [25] used a bilinear material model defining yield strength and tangent modulus for hemp polyester composites and found good agreement between experiments and simulations for tensile tests.

The aim of this study is to develop a methodology for the characterization of the impact behaviour of short natural fibre reinforced biocomposites through the combination of experimental impact testing, high speed imaging and finite element modelling. Polypropylene (PP) - hemp fibres biocomposites and PP - glass fibres composites with identical fibre volume fraction produced by twin-screw extrusion and injection moulding were chosen as material for this study. A drop-weight impact machine was used to characterize the behaviour of the composites over a wide range of impact energies (from 3 to $126 \mathrm{~J}$ ). Moreover, the implementation of a high speed camera during the impact test enabled the measurement of macro-cracks propagation and the tracking of the crack tip throughout the impact test. Based on these results and the tensile behaviour of the composites, a three-dimensional finite element model study was conducted so as to predict the impact behaviour of the composites.

\section{Materials and methods}

\subsection{Materials and composites manufacturing}

Polypropylene (PP) supplied by Faurecia Interior Systems (FIS, Meru, France) was used as the thermoplastic matrix. The mechanical and physical properties of the PP matrix are listed in Table 1.

Table 1. Tensile (ISO 527 standard) and thermal (measured by DSC with $10^{\circ} \mathrm{C} / \mathrm{min}$ heating rate) properties of PP matrix ; Et Young's modulus ; $\sigma_{m}$ ultimate tensile strength ; $\varepsilon_{b}$ strain at break ; $X_{c}$ degree of crystallinity; $T_{c}$ crystallisation temperature; $T_{m}$ melting temperature.

\begin{tabular}{lllllll}
\hline & $E_{t}(\mathrm{MPa})$ & $\sigma_{m}(\mathrm{MPa})$ & $\varepsilon_{b}(\%)$ & $X_{c}(\%)$ & $\mathrm{T}_{\mathrm{c}}\left({ }^{\circ} \mathrm{C}\right)$ & $\mathrm{T}_{\mathrm{m}}\left({ }^{\circ} \mathrm{C}\right)$ \\
\hline Mean & 1242 & 23.9 & 36.1 & 48.2 & 121.7 & 173 \\
\hline Standard deviation & 30 & 0.1 & 6.5 & 3.5 & 0.1 & 9
\end{tabular}


Hemp fibres (Cannabis sativa L., variety Fedora 17) supplied by Fibres Recherche Développement (FRD, Troyes, France) were used as reinforcement. The degree of retting was adjusted by the supplier for typical use in common composite applications. Hemp fibres presented an average length of $2 \mathrm{~mm}$. Their biochemical composition was characterized according to Van Soest method (standards NF EN ISO 13906 and NF V18-122): cellulose $(72.3 \% \pm 0.1)$, hemicelluloses $(7.7 \% \pm 0.1)$, lignin $(1.6 \% \pm 0.1)$, solubles $(18.1 \% \pm 0.2)$ and ashes $(0.4 \% \pm 0.1)$. The chopped glass fibres for the reference material were supplied by Owens Corning Vetrotex (OCV, Chambéry, France) under the trademark 248A. The sizing of these glass fibres was designed to be compatible with polypropylene matrix and developed for automotive applications. Average dimensions of glass fibres were $4.5 \mathrm{~mm}$ in length and $10 \mu \mathrm{m}$ in diameter.

Composite compounds were prepared using a co-rotating twin screw extruder BC-21 (Clextral, France) with a length (L) of $900 \mathrm{~mm}$, a screw diameter (D) of $25 \mathrm{~mm}$ and a (L/D) of 36. Temperature was set between $170^{\circ} \mathrm{C}$ and $180^{\circ} \mathrm{C}$ from the fibre feeding zone to the extruder die. The overall feed rate was $6 \mathrm{~kg} / \mathrm{h}$ and the screw rotation speed was $200 \mathrm{rpm}$. The extrudates were cooled in a water bath at the exit of the die, pelletized to $3 \mathrm{~mm}$ diameter and dried $48 \mathrm{~h}$ at $50^{\circ} \mathrm{C}$. A Krauss Maffei injection moulding machine was then used to prepare composite specimens in the form of square plates $\left(100 \times 100 \times 4 \mathrm{~mm}^{3}\right)$ for the impact tests and dumbbell specimens (ISO 527-1A) for the tensile tests. Temperature was set at $170^{\circ} \mathrm{C}$ with a screw speed of $150 \mathrm{rpm}$. Molten composites were injected with a pressure of 675 bars during $20 \mathrm{~s}$ and maintained in the mould during $12 \mathrm{~s}$ at $25^{\circ} \mathrm{C}$. The designation and composition of the different produced composites are given in Table 2.

Table 2. Composites produced and tested in the study

\begin{tabular}{lcc}
\hline sample designation & PP-H & PP-G \\
\hline PP mass fraction (\%) & 80 & 70 \\
\hline Fibre type & Hemp & Glass \\
\hline Fibre mass fraction $(\%)$ & 20 & 30 \\
\hline Fibre volume fraction $(\%)$ & 12 & 12 \\
\hline Young's modulus (MPa) & $2572 \pm 57$ & $6138 \pm 117$ \\
\hline Ultimate stress (MPa) & $24.5 \pm 0.1$ & $64.9 \pm 0.3$ \\
\hline Strain at break (\%) & $3.2 \pm 0.1$ & $1.9 \pm 0.0$
\end{tabular}




\subsection{Tensile properties of the composites}

Tensile mechanical properties of the biocomposites were measured with a Zwick TH 0101 testing machine equipped with an extensometer Zwick "clip-on" for the determination of the Young's modulus. The displacement speed was set to $1 \mathrm{~mm} / \mathrm{min}$ and $20 \mathrm{~mm} / \mathrm{min}$ for the determination of the Young's modulus and ultimate stress respectively according to ISO 527 standard. Ten samples were tested for each composite. Typical tensile curves of PP-H and PP-G composites are shown in Figure 1. Table 2 reports the Young's modulus, ultimate stress and strain at break values for the two composites. It should be pointed out that PP-H and PP-G composites present little and comparable standard deviations in their tensile properties.

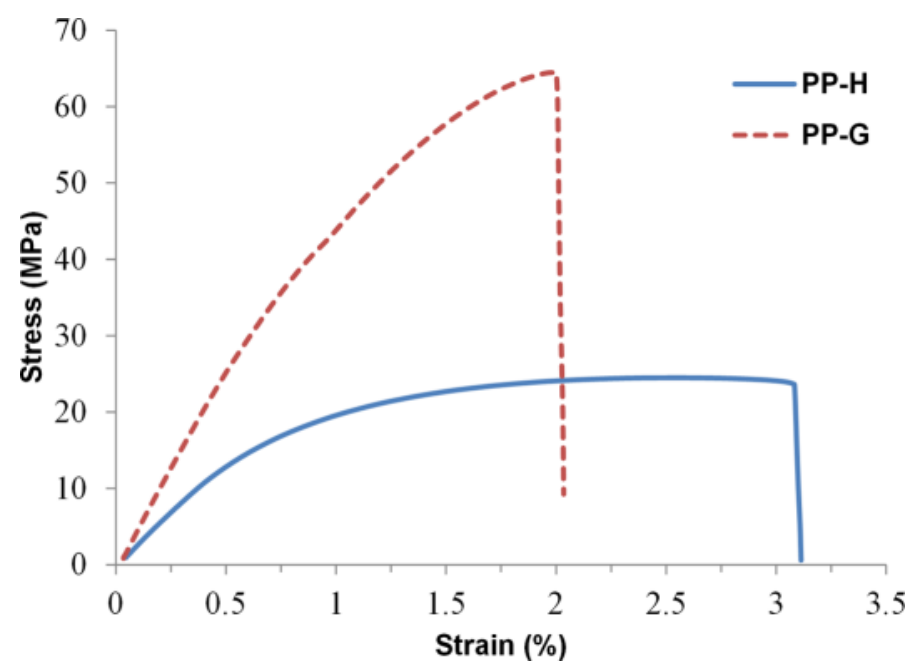

Figure 1. Typical tensile stress-strain curves of PP-H and PP-G composites.

\subsection{Characterization of the impact behaviour of the composites}

Impact tests were conducted on an Instron CEAST 9340 drop-weight impact machine allowing the impact force monitoring. The impact kinetic energy was varied by modifying the impactor height and weight and the resulting impact energies were $3,6,8,9,12$ and $126 \mathrm{~J}$. The samples were mounted, centred and clamped by a $40 \mathrm{~mm}$ diameter steel flanges fixture. They were then struck at their centre by a cylindrical steel striker with a hemispherical tip of $20 \mathrm{~mm}$ diameter. Five samples of each material were tested for the six impact energies. The force-time and force-displacement curves obtained were analysed. A visual evaluation of the broken samples was conducted in order to determine the critical energy needed for full penetration.

A high speed camera Phantom V711 (Vision Research - Ametek Materials Analysis Division) was added to the drop-weight impact set up enabling to capture $8000 \mathrm{fps}$ (frames per second) videos with a 
resolution of 800 x 1280 pixels, and a 0.109 mm/pixel calibration. The mirror setup as shown in Figure 2, allowed the real-time recording of the bottom face of the samples throughout the impact tests. The optical system includes the superLEDs array shining 180000 lux on the sample to enable exposure time as short as $240 \mu$ s to freeze the high speed motion and remove image blur.

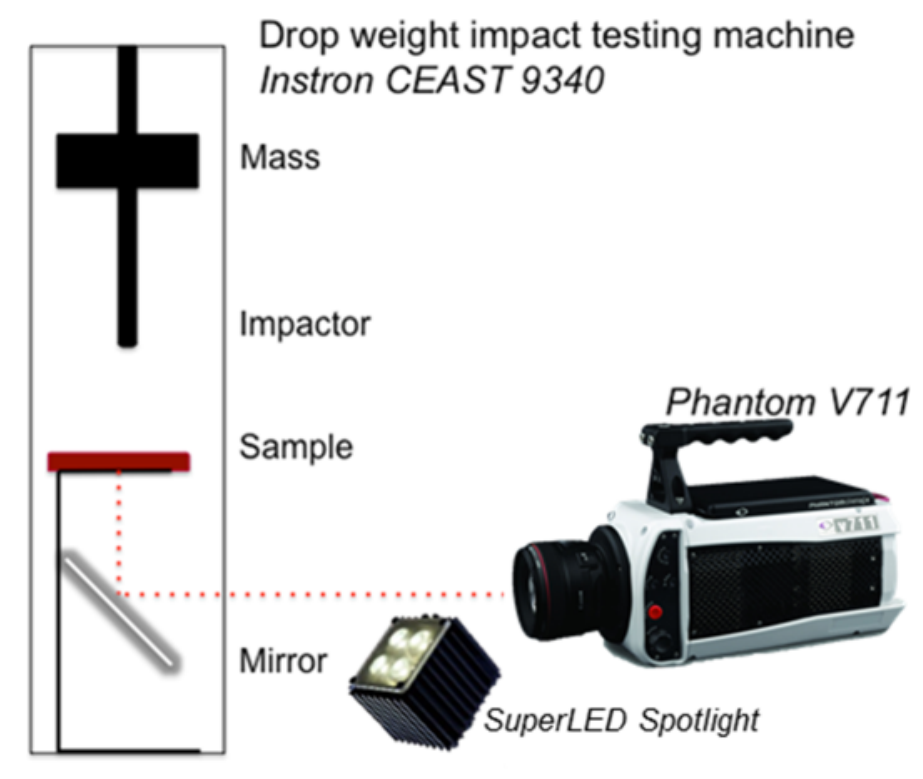

Figure 2. Scheme of the drop-weight impact machine Instron CEAST 9340 and high speed imaging setup.

An image analysis (using Phantom Camera Control software) was carried on the videos in order to measure the total macro-crack length cumulated within the samples every $0.25 \mathrm{~ms}$. First, an origin (O) was placed at the centre of the sample and the tips of the different macro-cracks (i.e. A, B, C, D,...) were tracked for each frame as it can be seen in Figure 3. Thus, the total crack length at any time $\mathrm{L}_{\text {crack }}(\mathrm{t})$ is given by Equation (1):

$$
\mathrm{L}_{\text {crack }}(\mathrm{t})=\mathrm{OA}(\mathrm{t})+\mathrm{OB}(\mathrm{t})+\mathrm{OC}(\mathrm{t})+\mathrm{OD}(\mathrm{t})+\mathrm{Oi}(\mathrm{t})
$$

Knowing that each video time code was synchronised to the contact onset, a correlation was established between the events occurring on the force / time / displacement curves obtained by the CEAST Data Acquisition and Analysis system (DAS) and the appearance of damages on the samples observable on the recorded images. 


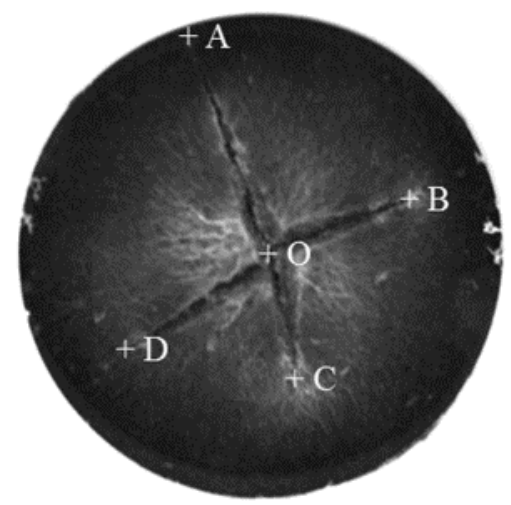

Figure 3. Principle of macro-cracks length tracking for a PP-H sample.

\subsection{Failure surface observations}

Failure surfaces of the broken samples obtained from the impact tests were observed in the thickness of the samples using a scanning electron microscope (SEM) (Quanta FEG 200, FEI Company). Samples were previously carbon coated and the acceleration voltage was set to $15 \mathrm{keV}$. The adhesion at the fibre/matrix interface was assessed on samples broken with impact energy of $12 \mathrm{~J}$.

\subsection{Three-dimensional finite element modelling}

The impact response of the glass fibre and hemp fibre reinforced polypropylene plate was modelled using the Finite Element software LS-DYNA. LS-DYNA is the desired FE code for the low velocity impact analysis of composite structures as it is a general-purpose FE code for analysis of large deformation dynamic response of structures based on explicit time integration (LS-DYNA manual [28]). The geometry of the FE model developed in LS-Prepost for the simulation of impact response of the composite plate is shown in Figure 4. The dimensions of the square plates were $100 \times 100 \times 4 \mathrm{~mm}^{3}$. The composite was modelled as a thick shell which enables a simplified method for defining composite layups. The composite plate has a clamped boundary condition along a $40 \mathrm{~mm}$ diameter hole of the support fixture similar to the one used in the experiments. 


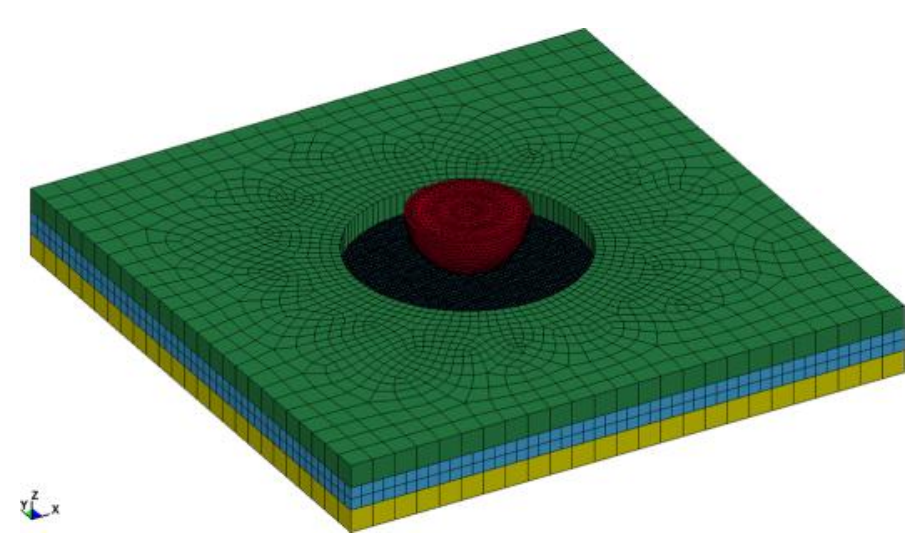

Figure 4. Geometry and finite element mesh of the composite plate, the impactor tip and the flanges.

The impactor hemispherical tip was modelled with 6355 tetrahedral elements, while the composite target was represented by 77768 thick shell elements with element length of $0.22 \mathrm{~mm}$ at the centre and $2 \mathrm{~mm}$ length in the periphery. The mesh on the composite plate was refined to have an adequately fine enough mesh in the central region of interest, i.e. areas of high stress gradients or large deformations. A mesh sensitivity analysis was conducted and this element size was the best compromise between calculation time and accuracy of the local material fracture representation.

The simplest models consider only the elasticity of the composite but tensile testing of the composite indicated that its behaviour is non-linear. Thus, a compromise solution is the use of Piecewise Linear Plasticity model available in the material library as MAT24. The elasto-plastic material constitutive law is based on the stress-strain curves obtained from the experimental tensile testing. The elastic Young's modulus defines the stress-strain relation up to the yield stress and above the yield stress, a curve defining effective stress and effective plastic strain coordinates is used to describe the plastic behaviour. An effective plastic strain criterion was used to define the erosion of elements, and hence the on-going damage within the plate. If the calculated effective plastic strain for any element exceeds the predefined value, the element is removed from the model and the simulation continues with the eroded model, i.e. the damaged plate.

An initial velocity is defined to the nodes of the hemispherical impactor. The density of the steel impactor is modified to obtain the same kinetic energy as in the experiments. Four initial velocities, 1.4, 1.98, 2.2 and $2.8 \mathrm{~m} / \mathrm{s}$ were simulated that correspond to initial impact energies of $3,6,9$ and $12 \mathrm{~J}$, respectively. To reduce the runtime, all simulations started with the impactor situated just $0.5 \mathrm{~mm}$ above the plate. An Automatic Surface to Surface contact was defined between the impactor and the composite plates. 
The time-history of the kinetic energy of the impactor and the internal energy of the composite target obtained from the LS-DYNA model is shown in Figure 5. The initial energy of the impactor is $3.07 \mathrm{~J}$ for this case and the corresponding internal energy at $\mathrm{t}_{0}$ is zero. As the impactor comes into contact with the target, there is energy transfer between the impactor and the composite. At $5.4 \mathrm{~ms}$, the kinetic energy of the impactor reaches zero at peak displacement and there is rebound afterwards. It can be seen that the internal energy of the target does not reach the initial kinetic energy of $3.07 \mathrm{~J}$ as some of the energy is lost as sliding energy and hourglass energy in the model. During the rebound phase, some of the energy of the plate is returned to the impactor. It can be observed that for the $3 \mathrm{~J}$ impact, there is considerable energy $0.57 \mathrm{~J}$ that is returned to the impactor. The final internal energy of the plate of $2.4 \mathrm{~J}$ corresponds to the energy dissipated in the plate in plastic deformation and damage. In the case of fully perforating impact, there is no rebound and the kinetic energy of the impactor remains zero.

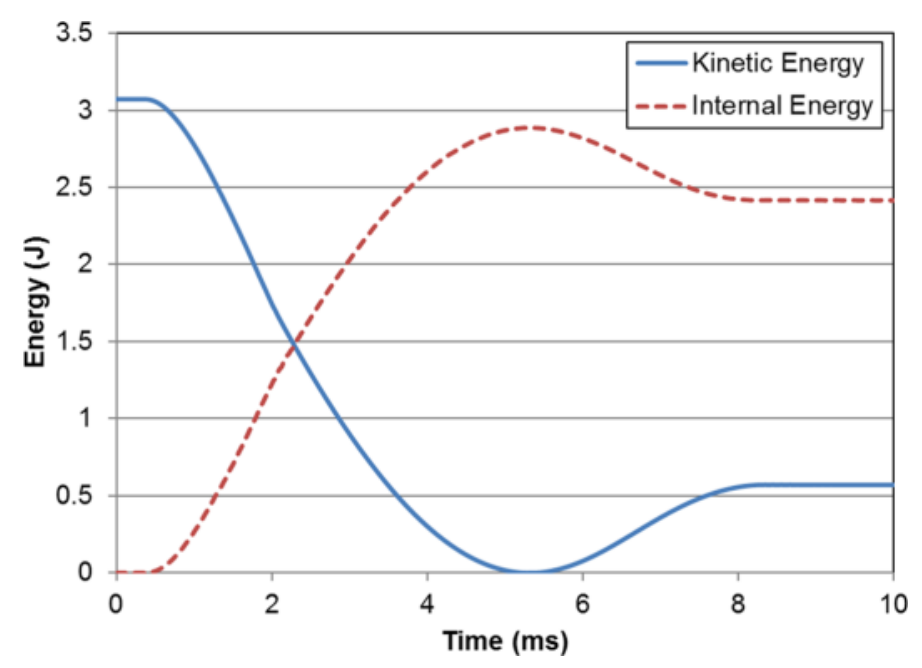

Figure 5. Energy history of the hemp composite plate for 3.07 J impact.

\section{Results and discussions}

\subsection{Experimental study of impact behaviour using drop-weight impact tests}

\subsubsection{Influence of impact energy}

Impact tests at increasing energy were performed in order to identify the critical impact energy at which the specimens were totally penetrated by the impactor. Figure 6 shows impacted PP-H and PP-G samples ordered by impact energy levels from 3 to $12 \mathrm{~J}$. Three main tendencies can be drawn according to energy level: (i) at low impact energies, i.e. 3 to $6 \mathrm{~J}$, the impacted specimen exhibit macro-cracks of 
moderate length that can be identified in the white zones related to crazing and cracking of the PP matrix; (ii) for intermediate energies, i.e. $9 \mathrm{~J}$ for PP-H and from 6 to $9 \mathrm{~J}$ for PP-G, macro-cracks reached their maximum lengths at the edge of the clamping steel plate; (iii) at high impact energies, i.e. $12 \mathrm{~J}$ and more, macro-cracks were widely opened due to the penetration of the impactor through the sample.

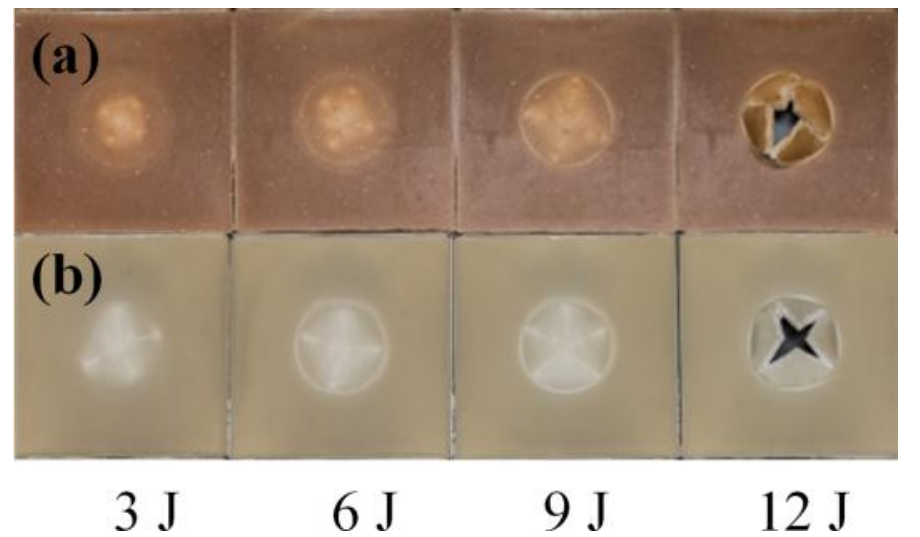

Figure 6. (a) PP-H and (b) PP-G samples broken on the drop-weight impact machine and ordered by increasing impact energy from $3 \mathrm{~J}$ to $12 \mathrm{~J}$.

The time history of contact force measured from the instrumented impactor for the hemp-PP composite at different impact energies is shown in Figure 7(a). A comparison of the force-time curves obtained for the PP-H and PP-G composites for $6 \mathrm{~J}$ impact is shown in Figure 7(b). Tests performed at low impact energies highlight a force increase as the impactor is in contact with the samples followed by a smooth decrease when the impactor leaves contact with the surface of the plate, which can be attributed to a rebound phase. This phenomenon occurred at 3 and $6 \mathrm{~J}$ for PP-H and only $3 \mathrm{~J}$ for PP-G composite as expected from the visual observations in Figure 6. Similar results were also reported by Santulli et al. [7-9], studying the impact behaviour of jute, hemp and flax fibres reinforced thermoset resins. Besides, the remaining whitening zone in the centre of the material corresponds to the irreversible crazing and cracking mechanisms that occurred within the PP matrix. Tests performed at intermediate impact energies, i.e. between $8 \mathrm{~J}$ and $9 \mathrm{~J}$ for PP-H and between 6 and $9 \mathrm{~J}$ for PP-G composite, exhibit a different behaviour as the smooth decrease in force related to rebound is not visible anymore. Indeed, a sudden drop in force is observed. At higher impact energies (9 J and above), the loading phase was followed by a drastic drop in force and a total penetration of the impactor through the samples. This drop in force is related to major damages within the material, either delamination (in the case of woven reinforced composites) or matrix cracking and fibre breaking / pull-out, as described by numerous authors [29-31]. 

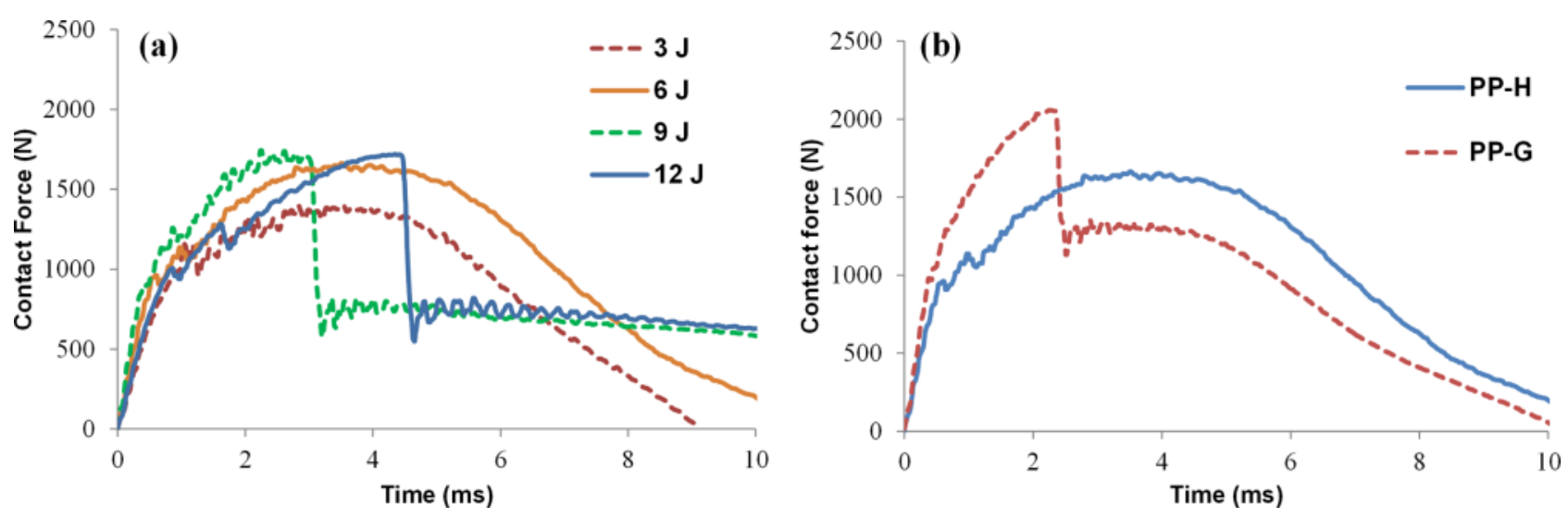

Figure 7. Contact force vs time curves for (a) PP-H according to the impact energy between 3 and 12J, (b)

Comparison of PP-H and PP-G for impact energy $6 \mathrm{~J}$.

The contact force-displacement curves for the PP-H and PP-G composites subjected to $6 \mathrm{~J}$ and $12 \mathrm{~J}$ impact are presented in Figure 8. Three main loading phases can be identified: (i) a linear domain at low deformation (i.e. shorter time) which corresponds to the elastic response of the materials, (ii) a non-linear domain at higher deformation which corresponds to the plastic strain of the materials and (iii) for high impact energy (above $9 \mathrm{~J}$ ), a final breakage phase which is characterized by a drastic drop of the force. As pointed out by Santulli et al. [7], an obvious higher elasticity of PP-G composite can be noticed when considering the slope of the contact force-time and displacement curves in the linear domain. Besides, even if different impact velocities were used to obtain each level of impact energy, it appears that the curves were superimposed in the linear domain, hence demonstrating that at this loading speed the pronounced viscoelastic character of the PP matrix had no significant influence on the response in the elastic domain.
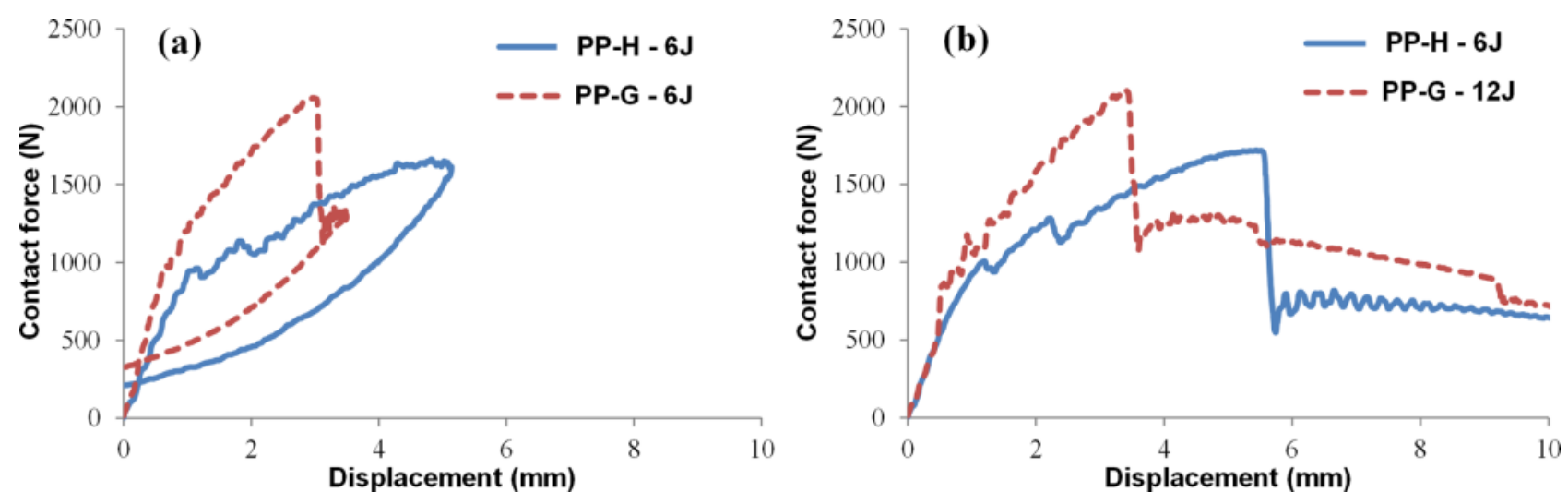

Figure 8. Contact force vs displacement curves for PP-H (blue) and PP-G (red) samples impacted at (a) $6 \mathrm{~J}$ and (b) 12J. 
In order to measure the absorbed energy upon impact, the force-displacement curves were divided into two different loading phases. In the first phase, the force increases until its maximum value $\left(\mathrm{F}_{\max }\right)$ followed by either (i) a slow decrease of the force corresponding to rebound or (ii) a sudden drop of the force corresponding to the breakage of the material. The area under the curve up to the displacement at $\mathrm{F}_{\max }$ corresponds to the absorbed energy upon impact. Various disturbances on the curves can be observed in this first phase suggesting the development of minor damages within the material. In the second phase, the force decreases smoothly (i) with negative displacement corresponding to rebound (low impact energy), (ii) or with non-regular force oscillations and positive displacement (intermediate and high impact energies) due to the friction of the impactor passing through the broken specimens, hence dissipating residual energy. The area under the force/displacement curve of this second phase (any positive displacement after reaching $\mathrm{F}_{\max }$ ) is thus considered as the energy absorbed due to frictions [12]. Although all materials exhibited the same kind of force/displacement response within the same range of impact energies, it should be noticed that PP-H composites fully broke at $9 \mathrm{~J}$ whereas PP-G composite broke at threshold energy of $8 \mathrm{~J}$. This suggests that $\mathrm{PP} /$ hemp biocomposites may be submitted to higher impact energies than PP/glass composites without complete failure.

Table 3 presents the peak force $\left(\mathrm{F}_{\max }\right)$ and the displacement at $\mathrm{F}_{\max }$ for both composites as a function of the impact energy. For a given impact energy, the maximum impact force $\left(F_{\max }\right)$ reached by the PP-G composite tends to be higher than those of PP-H biocomposites, e.g. $20 \%$ higher at $12 \mathrm{~J}$ with $2099 \pm 17 \mathrm{~N}$ and $1753 \pm 31 \mathrm{~N}$ for PP-G and PP-H, respectively. On the other hand, the deformations at break for PP-G composite are lower than those of PP-H biocomposites, e.g. 50\% higher at $12 \mathrm{~J}$ with $3.52 \pm 0.2 \%$ and $5.4 \pm$ $0.4 \%$ for PP-G and PP-H respectively. Those results are believed to be related to differences in fibre stiffness and strain. Indeed, several authors showed a significant difference between hemp and glass fibres Young's modulus ranging from 14 to $70 \mathrm{GPa}$ [32-35] and $73 \mathrm{GPa}$ [36,37], respectively. Moreover, although hemp fibres have a lower elongation at break than glass fibres due to local defects and weak points (1.6-3\% [33] and 4.6-4.8\% [38] respectively), their composites show an opposite trend with significantly higher elongation at break (see tensile curves for PP-H and PP-G in Figure 1). It can be assumed that the higher stiffness of glass fibres tends to reduce the ductility of the composite during the impact. Differences in the 
quality of interfacial adhesion and failure mechanisms could also be responsible for the lower elongation at break measured for glass fibres composites.

Table 3. Peak force $F_{\max }$ and displacement at $F_{\max }$ for PP-H and PP-G according to the impact energy.

\begin{tabular}{lcccccccccccc}
\hline & \multicolumn{1}{c}{ PP-H } & \multicolumn{1}{c}{ PP-G } \\
\hline Impact Energy $(\mathbf{J})$ & 3 & 6 & 8 & 9 & 12 & 126 & 3 & 6 & 8 & 9 & 12 & 126 \\
\hline $\mathbf{F}_{\max }(\mathbf{N})$ & 1414 & 1689 & 1728 & 1760 & 1753 & 1771 & 1767 & 1993 & 2028 & 1990 & 2099 & 2069 \\
\hline Std Deviation & 27 & 26 & 15 & 63 & 31 & 19 & 24 & 46 & 43 & 26 & 17 & 35 \\
\hline Displacement at $\mathbf{F}_{\max }(\mathbf{m m})$ & 1.1 & 4.6 & 5.5 & 5.2 & 5.4 & 5.1 & 1.2 & 3.0 & 3.3 & 3.3 & 3.5 & 3.5 \\
\hline Std Deviation & 0.0 & 0.1 & 0.4 & 0.3 & 0.4 & 0.4 & 0.0 & 0.2 & 0.2 & 0.1 & 0.2 & 0.0
\end{tabular}

In other studies, higher deformation at break and significantly lower peak load were also measured for various hemp fibre reinforced composites. Santulli et al. [7-9] compared the impact behaviour of a flax / epoxy composite to a glass / epoxy composite with similar weight ratio reinforcement on a drop-weight impact test, and found a better impact resistance for the glass reinforced ones. Patel et al. [5] and Scarponi et al. [6] also showed that glass fibres reinforced polyester and epoxy composites have a slightly higher energy absorbed at breakage than hemp reinforced biocomposites. However at low fibre volume fraction $(<20$ vol\%), the difference was much smaller. Caprino et al. $[11,12]$ also noted a higher absorbed energy at failure for carbon or glass reinforced composites when compared to biocomposites, even if a higher impact energy was needed to initiate damages in hemp fibres reinforced epoxy composite.

Nevertheless, it should be noticed that in several studies, fibre volume fractions are different, i.e. 50 vol $\%$ for carbon fibres reinforced composites, 47 vol\% for glass fibres reinforced ones and 30-35 vol\% for hemp fibres reinforced ones, which does not allow to draw clear conclusions on the reinforcing effect of hemp fibres. Moreover, all the above described observations were performed on the total absorbed energy during the impact tests including the friction phase. In the present study, only the absorbed energy until $\mathrm{F}_{\max }$ was considered as the remaining absorbed energy is widely influenced by the friction properties of the impactor and the broken material and hence less representative of the impact resistance of the material.

Figure 9 shows the evolution of the absorbed energy at $F_{\max }$ as a function of the impact energy. It can be easily observed that a plateau is reached above $12 \mathrm{~J}$ for both PP-H and PP-G composites. Considering the standard deviations in the transitory phase (between breakage and full impactor penetration: 8-12 J for PP-H 
composite and 6-12 J for PP-G composite), it is evident that once the maximum energy that can be absorbed by the material is reached, further increasing the initial impact energy does not produce corresponding increase in absorbed energy. This is proved by the $126 \mathrm{~J}$ impact case, and it can be seen that the same amount of energy is absorbed from 8 to $126 \mathrm{~J}$ for PP-H and PP-G composites. This result evidences the existence of three different breaking responses depending on the impact energy. At low impact energy (up to $6 \mathrm{~J})$, radial macro-cracks are initiated and slightly propagated. The sample does not undergo a major failure and the absorbed energy is limited. At intermediate energy (from 6 to $9 \mathrm{~J}$ ), cracks are fully propagated but the impact energy is not sufficient to fully penetrate the sample. Nevertheless, the material undergoes a major failure leading to a sharp force drop and the total energy that can be absorbed by the material under breakage is reached. Finally, at high impact energy, macro-cracks are fully propagated and the material exhibits the same drop in force. The higher impact energy leads to a complete penetration of the impactor within sample but the absorbed energy is similar since no additional macro-cracks propagate.

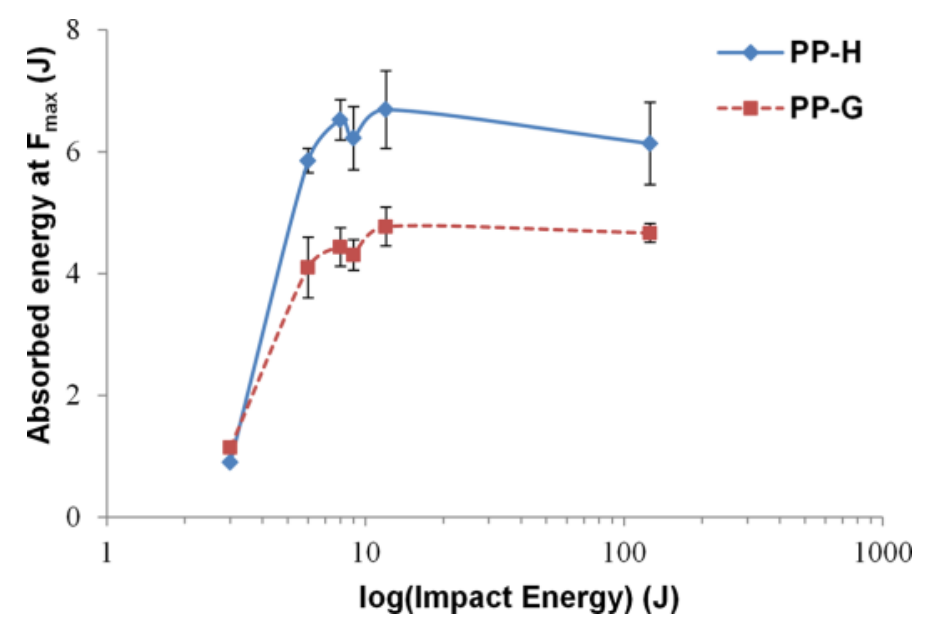

Figure 9. Absorbed energy at $\mathrm{F}_{\max }$ according to the impact energy for PP-H and PP-G composites.

Concluding, by comparing PP-H and PP-G composites at the same fibre volume fraction (12 vol\%), we found that the absorbed energy until $\mathrm{F}_{\max }$ for PP-G composite is much lower than for PP-H composite (highest difference of $40 \%$ being reached at $12 \mathrm{~J}$ ). This is believed to be due to a better energy dissipation within the biocomposite microstructure related to higher plastic strain and a potential interfacial decohesion phenomenon attributed to a poor adhesion at PP / fibre interface [39]. 


\subsubsection{Failure surface observations and adhesion at the fibre /matrix interface}

An analysis of literature data on the interfacial shear strength (IFSS) of PP / hemp fibres and PP / glass fibres, as measured by fibre microbond or pull-out tests, revealed that IFSS ranges from 3.3 to $5.8 \mathrm{MPa}$ for PP / hemp [40,41], whereas PP / sized glass fibres have IFSS values ranging from 8 to $10.2 \mathrm{MPa}$ [42]. This significant difference can be primarily explained by the fact that commercial grades of glass fibres are sized to be compatible with the host matrix while it is not the case with hemp fibres. Indeed, PP / bare glass fibres has an IFSS similar to PP / hemp, i.e. ranging from 3 to $6 \mathrm{MPa}$, hence highlighting the important role of the sizing on the IFFS of PP/ glass [42,43].

Failure surfaces in the thickness of PP-H and PP-G samples broken at $12 \mathrm{~J}$ were observed by SEM so as to qualify the interfacial adhesion between the matrix and the two fibre types. As seen in Figure 10, no clear difference was found between the failure surfaces obtained with the untreated hemp fibres and the sized glass fibres, as they all primarily exhibit fibre pull-out phenomena and matrix failures with few fibres breakage. Moreover, no residue of polymer matrix could be found onto fibres surface even for PP-G composites, although glass fibre sizing was formulated for PP matrix. There observations conflict with the significant differences in IFSS values reported in literature for PP / glass and PP / hemp. However, it should be pointed out that micromechanical tests (microbond / pull out tests) used to determine IFSS for short fibres reinforced composites are usually conducted at very low strain rates, whereas impact testing involve very high strain rates. Our observations thus highlight that the quality of interfacial adhesion and its role on composite damage could be strain rate dependent. In this regard, Thio et al. [39] found that the positive relation between impact toughness and weaker adhesion in PP / glass particles systems became less pronounced as strain rate was increased. Nevertheless, the authors could not conclude on the origin of this strain rate dependency, being either related to the debonding mechanism itself or to the plastic strain characteristics of the matrix polymer.

In any case, our SEM observations are characteristic of a weak interfacial adhesion which could greatly influence the absorbed energy at breakage. Indeed, Russo and its co-authors [44-46] showed that such weak interfaces lead to adhesive interfacial failure and higher strain at break during impact promoted by fibres slipping that is known to dissipate a considerable amount of energy. George et al. [47] have shown for flax fibres reinforced epoxy composites that interfacial compatibilisation can lead to lower impact strength. 
For these authors, cohesive interfaces obtained by fibre treatments such as organosilanes only promoted increases in tensile stiffness and strength to the detriment of impact properties. In contrast, Patel et al. [5] found that fibre surface treatments (silane and alkaline) promoting interfacial cohesion led to higher absorbed energy upon impact for hemp fibre reinforced polyester composites.

The differences in fibre shape factors (length over diameter) could also influence the stress transfer mechanisms upon loading and hence the impact behaviour. A microstructural analysis was performed on PP$\mathrm{G}$ and PP-H composites (not shown). We found median fibre shape factors of 3.5 and 2.7 for PP-G and PP$\mathrm{H}$, respectively. Nevertheless, in both cases, fibre lengths were far from the critical fibre length for optimal stress transfer. Besides, Oksman et al. [48] pointed out that fibre shape factor has no critical influence when the interfacial adhesion is poor as is the case in this study. Based on SEM micrographs, the failure of PP-H and PP-G composites thus appears dominated by matrix failure and fibre pull-out, independent of the fibre type.
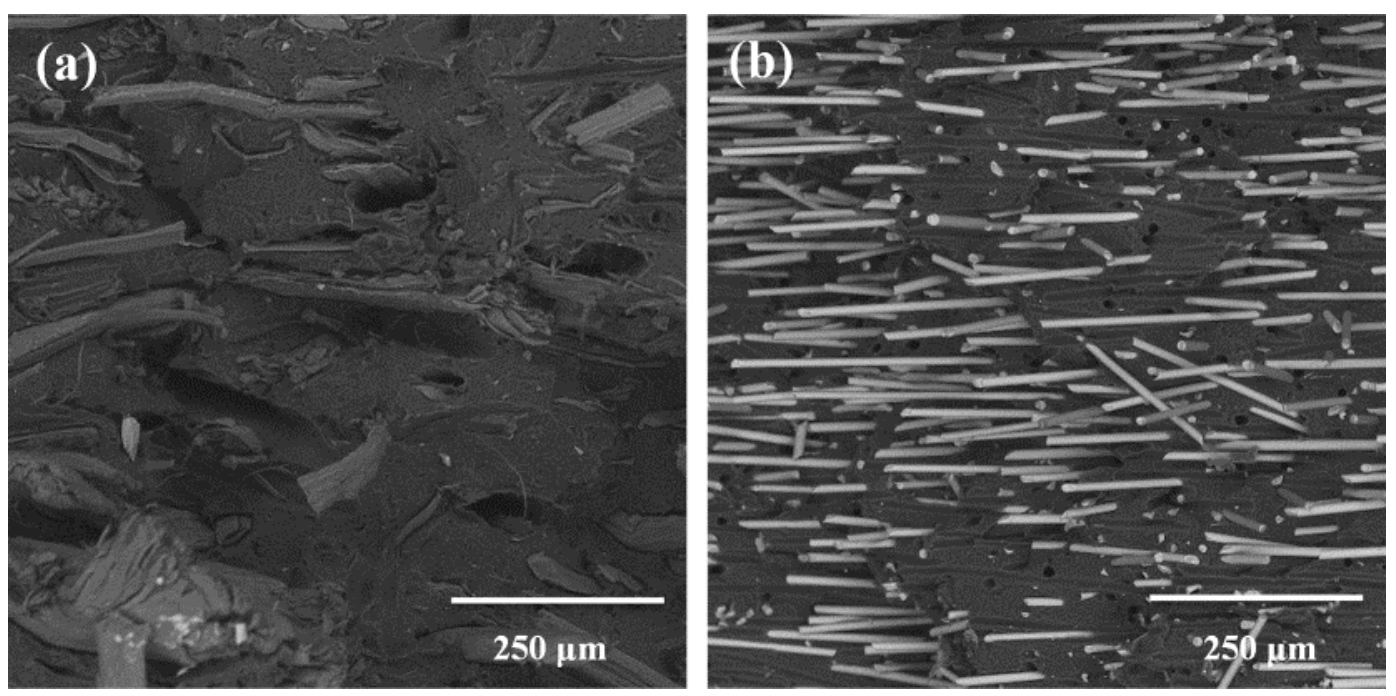

Figure 10. SEM micrographs of failure surfaces of samples broken at $12 \mathrm{~J}$ impact for (a) PP-H and (b) PP-G composite.

\subsubsection{Impact behaviour analysis using high speed imaging}

\subsubsection{Description of impact events: image analysis versus force-displacement}

\section{curves}

A high speed imaging acquisition system has been implemented on the drop-weight impact machine so as to correlate the occurrence of events on the force-displacement curves and appearance and propagation 
of macro-cracks in the composite specimens as shown in Figure 11 in the case of a PP-H biocomposite impacted at $12 \mathrm{~J}$ (see also videos for PP-H and PP-G composites impacted at $3 \mathrm{~J}$ and $12 \mathrm{~J}$ ).

All the force-displacement curves obtained from drop-weight impact tests exhibit several disturbances during the loading phase seen as small and short drop in force and labelled events (1), (2), (3) and (4) in Figure 11. Synchronising the recording of the high speed imaging and the impact test, it was possible to correlate these events to the appearance of macro-cracks on the bottom face of the samples. For this particular test (PP-H at $12 \mathrm{~J}$ ), the sampling frequency was $200 \mathrm{pts} / \mathrm{ms}$ on the impact force curves and 4 frames/ms on the recorded videos. The first drop in force occurred at $8.13 \mathrm{~ms}$ (event (1) on the curve) and the two first radial macro-cracks appeared at $7.80 \mathrm{~ms}$ (picture (1). This phenomenon was accompanied by a whitening of the sample related to crazing phenomenon. "Drop in force" events (2) and (3) occurred at $8.60 \mathrm{~ms}$ and $9.70 \mathrm{~ms}$, respectively, while the third and fourth macro cracks were observed at 8.30 and $9.30 \mathrm{~ms}$ (pictures (2) and (3)). It should be pointed out that a constant time gap of roughly $0.30 \mathrm{~ms}$ was noticed between the "drop in force" events and the appearance of the macro-cracks. This time gap is assumed to be due to a synchronization fault in the recording of both signals, i.e. imaging and force-displacement data, and related to a short delay of the DAS acquisition system of the drop-weight impact machine. Nevertheless, the appearance of new macrocracks was a temporal phenomenon very close to the drop in force observed on the curves and they can thus be directly correlated. The more remarkable event on the force curve was undoubtedly the major force drop that occurred at the event (4). This event imputed to the total breakage of the material, was found to be related to the moment at which one of the four propagating macro-cracks reaches the edge of the clamped sample. The drop in force occurs at $12.07 \mathrm{~ms}$, while the image related to the macro-crack reaching the edge was taken at $11.80 \mathrm{~ms}$. A time gap of the same order ( $0.3 \mathrm{~ms})$ was again observed. Events (5), (6) and (7) are related to the smooth decrease of the force occurring when the impactor fully penetrates the sample, spreading the four triangles formed after the complete macro-cracks propagation. 


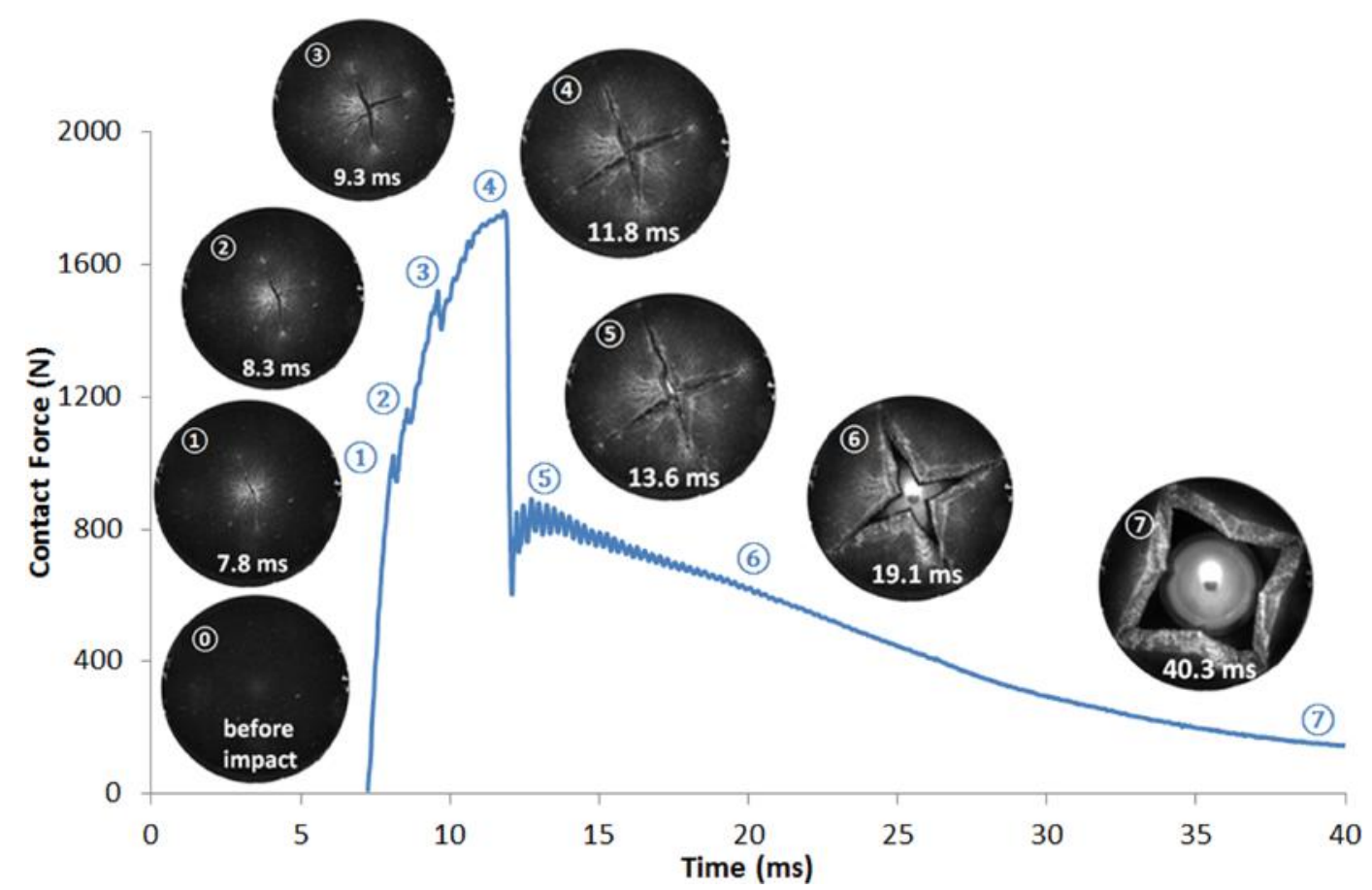

Figure 11. Contact force versus time and associated time tagged cliches corresponding to the different events on the curve for a PP-H sample impacted at $12 \mathrm{~J}$.

This analysis was carried out for all impact energies and the two composites. Similar phenomena were observed in all cases. For low impact tests ( 3 and $6 \mathrm{~J})$, the appearance of short macro-cracks occurred at the time of small drop in force. For higher impact tests ( 8 to $126 \mathrm{~J}$ ), the major drop in force, corresponding to the total breakage of the material, always occurred when one of the macro-cracks reaches the edge of the clamped sample.

\subsubsection{2. $\quad$ Crack length propagation during impact}

Tracking the tip of each macro-crack appearing on the samples during impact enabled the quantification of the cumulated length of macro-cracks over time as seen in Figure 12. Correlating the force-time curve to the cumulated crack length, it is observed that sudden increases in crack length are related to drop in force. Indeed, the first sharp increase in crack length of $13.68 \mathrm{~mm}$ measured at $7.80 \mathrm{~ms}$ can be correlated to the first drop in force ( $8.13 \mathrm{~ms}$, event (1) on Figure 11). Accordingly, the second and third crack length increments (22.98 $\mathrm{mm}$ at $8.37 \mathrm{~ms}$ and $36.10 \mathrm{~mm}$ at $9.37 \mathrm{~ms}$, respectively) correspond to the second and third drop in force (8.60 ms and $9.70 \mathrm{~ms}$, events (2) and (3) on Figure 11, respectively). These sudden increments in crack length can be due to both the appearance of new macro-cracks and the propagation of already initiated ones. 
Besides, it should be pointed out that the same time gap (about $0.30 \mathrm{~ms}$ ) between the force curve and the crack length increments was found.

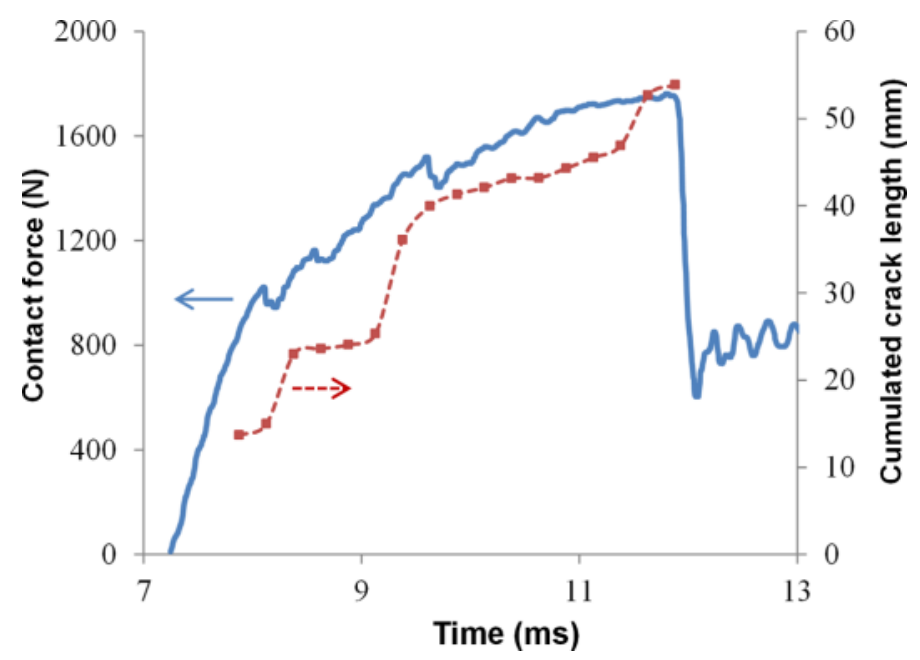

Figure 12. Cumulated macro-crack length over time (dashed line) correlated to the force curve (solid line) measured along a $12 \mathrm{~J}$ impact test on a PP-H sample.

The comparison of cumulated crack lengths reached at breakage for PP-H and PP-G composites is given in Figure 13 a). Despite a higher absorbed energy at break whatever the impact energy (Figure 9), PP$\mathrm{H}$ exhibits the same cumulated length of macro-cracks for a given impact energy when compared to PP-G composites. Moreover, the cumulated crack length reached a plateau for impact energies higher than $8 \mathrm{~J}$. A maximum cumulated crack length of roughly $50 \mathrm{~mm}$ was indeed reached by all composite specimens. This maximum value of cumulated crack length was not as high as expected if considering that the four macrocracks initiated in the plate would all reach the clamped edges of the sample. Indeed, in this case, a cumulated crack length of 4 times the radius of the clamped specimen, i.e. $80 \mathrm{~mm}$, would be reached. This results highlights that the full breakage of the material and related large drop in force occurs as soon as one of the macro-cracks reaches the clamped edge of the sample.

Comparing the cumulated crack length versus the absorbed energy at $\mathrm{F}_{\max }$ of PP-H and PP-G composites (Figure $13 \mathrm{~b}$ ), it seems obvious that for a given crack length, PP-H biocomposites absorb much more energy $\left(\mathrm{p}\right.$-value $=1.01 \times 10^{-5}$ for absorbed energy data and $\mathrm{p}$-value $=0.19$ for cumulated crack length data, based on the statistical non-parametric Mann \& Whitney U test). This result evidences that despite having similar fracture growth patterns, the energy absorbed during crack propagation is significantly higher for PP-H biocomposite as compared to PP-G composite. This could be related to differences in failure 
mechanisms, adhesive interfacial failure and fibre pull-out phenomenon being predominant for the biocomposites (Figure 10). Besides, crazing phenomenon within the PP matrix might play an important role in the processes of energy absorption during impact. Unfortunately, considering the very short duration of an impact, it was not possible to collect a sufficient number of images while keeping the high resolution required to analyse crazing phenomenon in details.
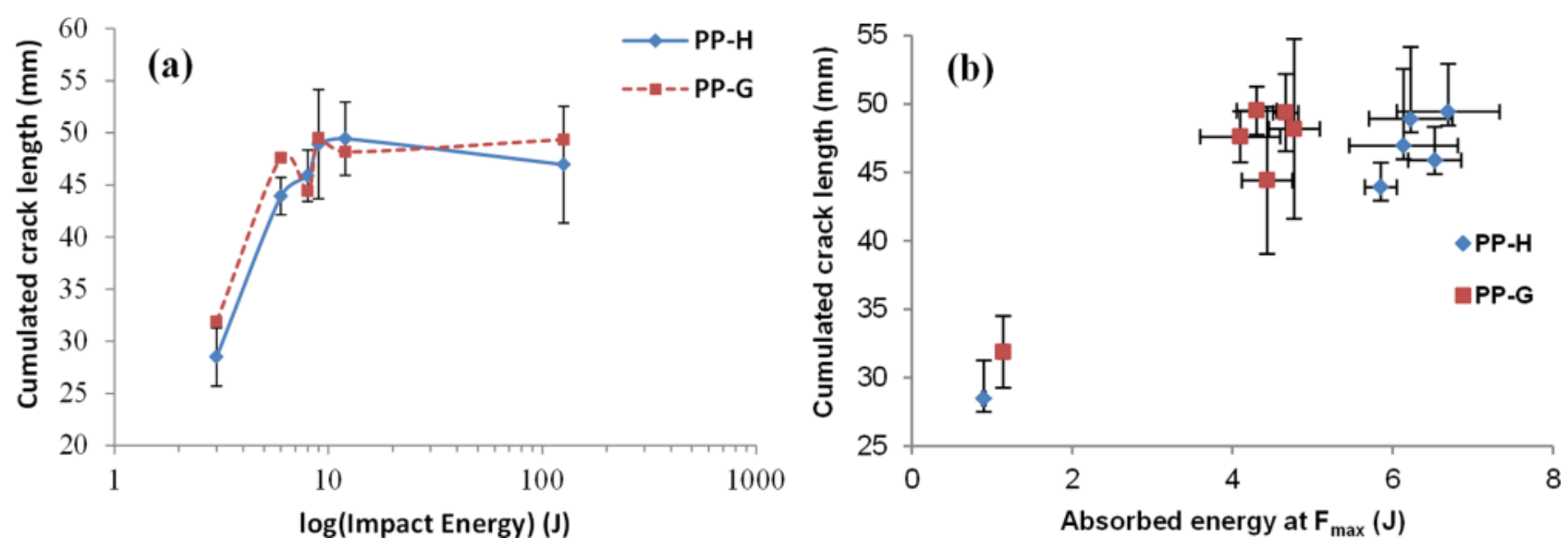

Figure 13. a) Cumulated crack length at $\mathrm{F}_{\max }$ versus impact energy for PP-H and PP-G composites, b) Cumulated crack length at $\mathrm{F}_{\max }$ versus absorbed energy at $\mathrm{F}_{\max }$ for PP-H and PP-G composites.

\subsection{Numerical study of impact behaviour using three-dimensional finite element modelling}

The simulated mechanical response of the plate during impact is usually recorded and analysed in terms of peak load, absorbed energy, and deflection at peak load. Figure 14 shows the simulated force-time and displacement-time curves for $3 \mathrm{~J}$ impact on PP-H biocomposite. The impactor displacement history shows the loading phase up to the maximum displacement of $3.8 \mathrm{~mm}$. It can be seen that after peak force of $1050 \mathrm{~N}$, there is a sharp drop in the force corresponding to the creation of macro-cracks. At the end of the loading phase at $5.1 \mathrm{~ms}$, there is a rebound of the impactor seen as a decrease on the displacement curve. 


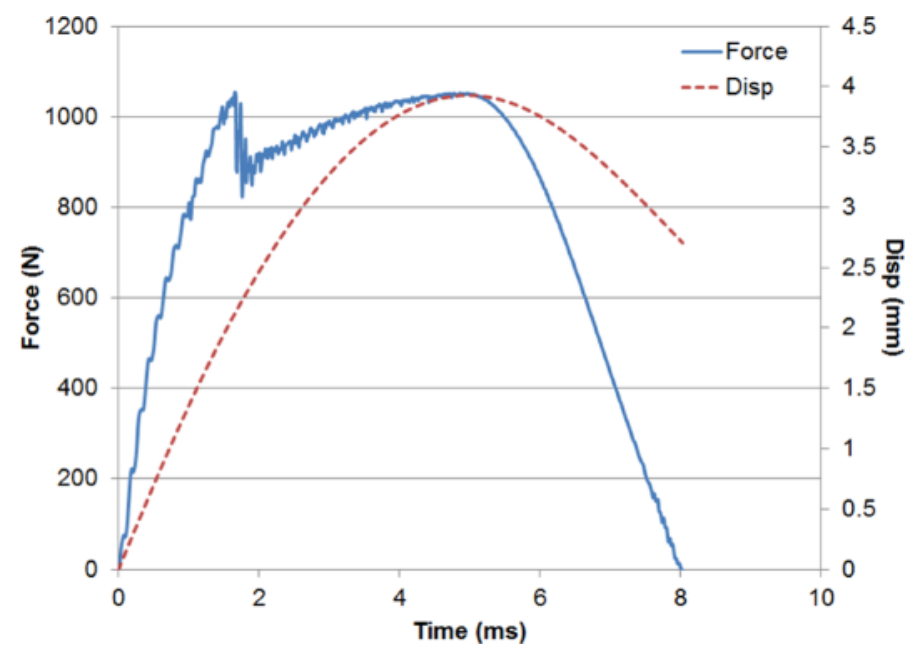

Figure 14. Typical force and displacement history for $3 \mathrm{~J}$ impact on PP-H biocomposite.

Figure 15 shows the bottom surface of the plate at different time intervals to show the initiation and propagation of damages for the case of $3 \mathrm{~J}$ impact. It can be seen that there is highly localised out-of plane displacement at the point of impact (see also FE videos of displacement for PP-H composite impacted at $3 \mathrm{~J}$ and $12 \mathrm{~J}$ ). At time $=1.74 \mathrm{~ms}$, there is crack initiation and the first eroded elements are visible. At time $=2.6$ $\mathrm{ms}$, the crack length has increased in the principal loading directions, indicating propagation of damage in the composite plate. At time $=4.6 \mathrm{~ms}$, which corresponds to the end of the loading phase, the crack has grown to the maximum length for the particular loading case and there is no further crack growth during the unloading phase.

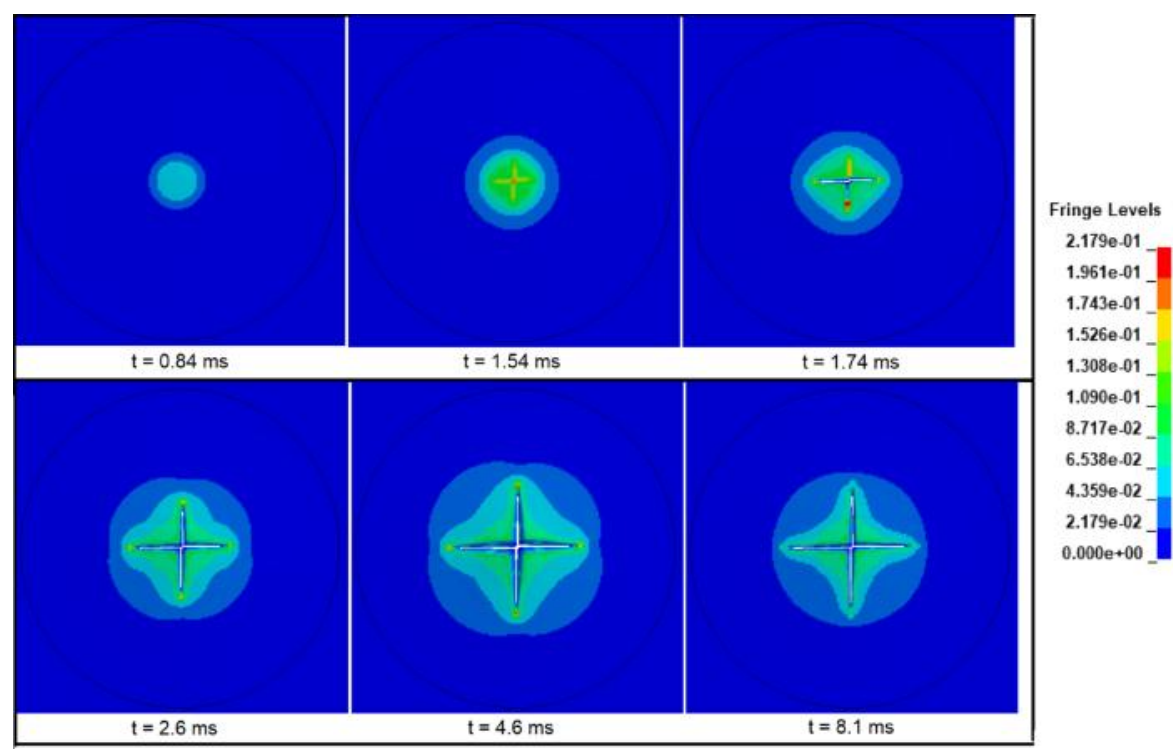

Figure 15. Mean effective strain contours throughout propagation of impact damage in PP-H biocomposite model for $3 \mathrm{~J}$ impact. (see also FE videos of strain for PP-H composite impacted at $3 \mathrm{~J}$ and $12 \mathrm{~J}$ ) 
The damage of the composite plate was simulated using erosion criteria. A damage parameter D is defined to express the volume of the eroded elements. Since the mesh around the point of impact is very fine and the cracks are typically one element wide, the volume of the eroded elements as a percentage of the total volume of the plate is very small (of the order of $1.10^{-3} \%$ ). Figure 16 shows the propagation of failure in the PP-H biocomposite plate for $3 \mathrm{~J}$ and $12 \mathrm{~J}$ impact. It can be seen that the initiation of cracks occurs at $2 \mathrm{~ms}$ and $0.98 \mathrm{~ms}$ for the two impact cases, respectively. There is a rapid initial crack followed by steady increase in the damage. The amount of damage is evidently higher for the $12 \mathrm{~J}$ impact when compared to $3 \mathrm{~J}$ impact. It is also interesting to note that there is a massive increase in the eroded volume at perforation for $12 \mathrm{~J}$ impact at $5.1 \mathrm{~ms}$.

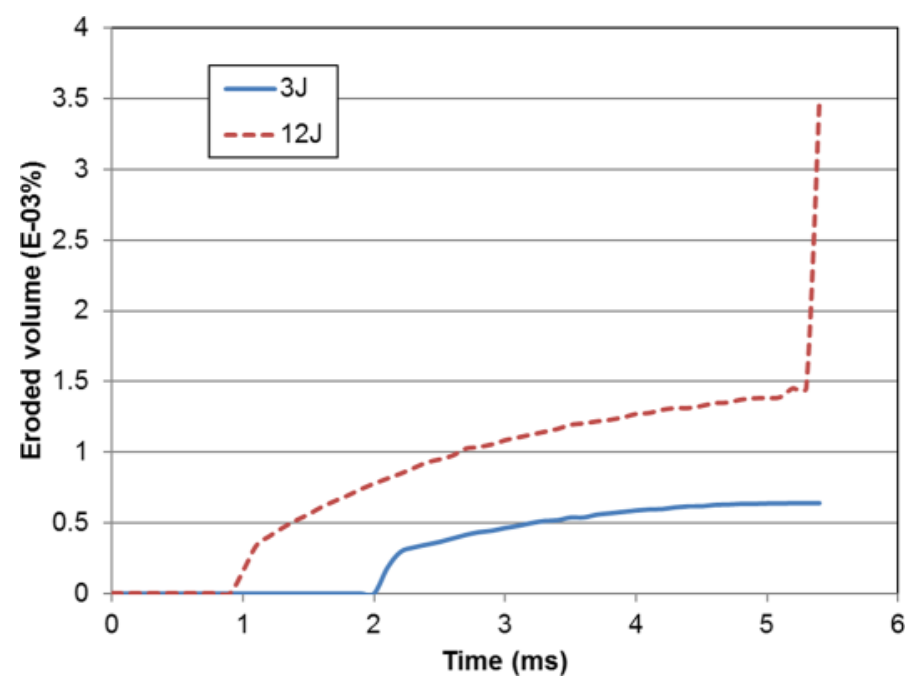

Figure 16. Eroded volume of elements for 3 and $12 \mathrm{~J}$ impact case for PP-H biocomposites.

The validation of the finite element model was accomplished by the comparison of the force-time history obtained from the LS-DYNA model and the drop tower experiments. Additionally, a qualitative comparison of the crack growth pattern of the composite was achieved so as to determine the ability of the simulation to reproduce the phenomena observed during the experiment. Figure 17 shows the force-time history as well as bottom surface of the PP-H biocomposite for impact energy of $3 \mathrm{~J}$ and $12 \mathrm{~J}$. A comparison of the bottom surfaces impacted at $3 \mathrm{~J}$ and $12 \mathrm{~J}$ and observed with high speed imaging at the end of the loading phase is also shown in the figure.

For the $3 \mathrm{~J}$ impact case, it can be seen from the comparison of the force curve that there is good overall comparison with the experiment. The force increases quasi-linearly till the first macro failure seen 
from the drop in the force values (Figure 17 a). In the case of the LS-DYNA model, this crack initiation force is about $1030 \mathrm{~N}$ while for the experiment, the critical force is $1120 \mathrm{~N}$. The model also overestimates the loss of stiffness due to this failure compared to the experiment. This can be explained by the fact that the failure is modelled using an erosion criteria which instantly deleted the elements that have exceeded the failure strain. A progressive damage model would be more suitable to predict the loss of stiffness due to the accumulation of damage. The crack pattern and length at the end of the loading phase are similar to the composite plate impacted using the drop tower (Figure $17 \mathrm{~b}$ and $\mathrm{c}$ ). It should be noticed that the total duration of the impact is under-estimated in the model; $8 \mathrm{~ms}$ compared to $9.2 \mathrm{~ms}$ for the experiment.

While the lower energy impact caused only crack initiation, it is evident from the drop tower experiment at $12 \mathrm{~J}$ that there was crack propagation and complete perforation of the plate (Figure $17 \mathrm{e}$ and $\mathrm{f}$ ). The force-time curves shows that the beginning of the loading phase and the critical force for the first initiation of cracks at around $1000 \mathrm{~N}$ is well reproduced by the LS-DYNA simulation (Figure $17 \mathrm{~d}$ ). The loss of stiffness due to these cracks is higher for the model due to the erosion of the failed elements. However, the model was able to simulate the perforation at $5.1 \mathrm{~ms}$ and the corresponding drop in the force. It is important to note that the material parameters input to the FE model, including the erosion parameters of maximum effective strain and number of integration points were the same for the different impact energies. The bottom surface of the plate observed from the experiments and the FE model also exhibit similar behaviour (Figure $17 \mathrm{e}$ and f). In the case of the higher energy impacts, since there is no rebound phase, the image at the time of the sharp drop in force corresponding to penetration damage was chosen. The crack extends almost up to the edge of the fixture and additionally some failure can be observed in the clamped edge of the plate. 

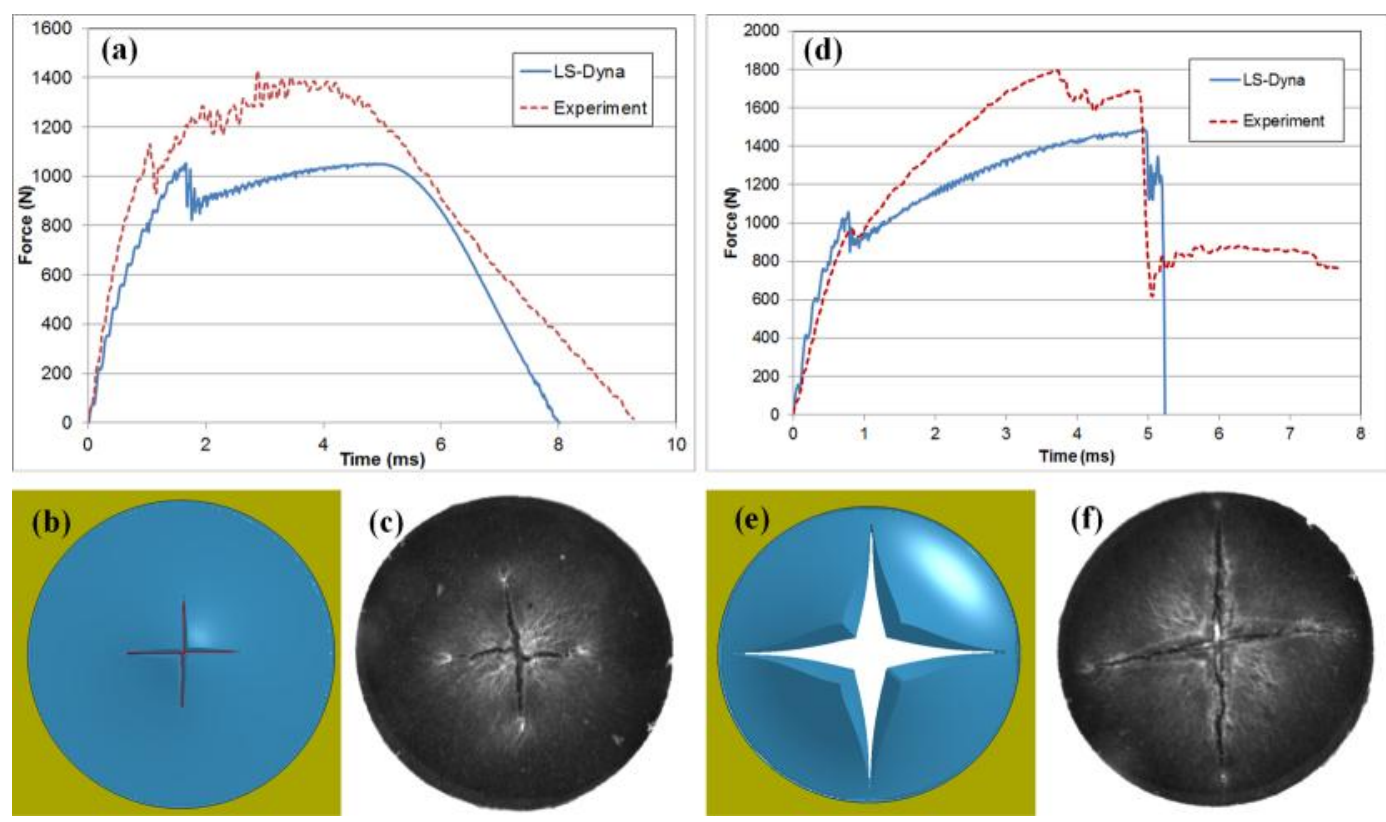

Figure 17. Comparison of force-time history for (a) $3 \mathrm{~J}$ and (d) $12 \mathrm{~J}$ impact of PP-H biocomposite; Bottom surface of plates at the end of the loading phase from ( $b$ and e) LS-DYNA model and from (c and f) drop tower experiments.

One of the important outcomes of the model is its ability to correlate the crack length from the simulations with the experimental crack length measured from the high speed camera images. Table 4 shows the cumulated crack lengths measured for 3, 6, 9 and $12 \mathrm{~J}$ impact energy from the image analysis and from simulations. It can be seen that there is less than $12.63 \%$ of difference between the model and the experiment. The modelling of impact damage with simple erosion criteria thus overcomes the difficulties of complex damage models such as Johnson Cook Damage model, which requires many additional experimental tests to estimate the input parameters, while still being able to predict with good agreement the impact behaviour measured experimentally, both in terms of force-time history and macro-cracks propagation. It should be pointed out that the developed model could be improved by considering the strain rate effects for example by using Cowper Symonds model [26] [28]. Obviously, the strain rate dependency of the mechanical behaviour of composites would need to be investigated by mechanical testing at increasing strain rates so as to determine the parameters to include in the model. An improved model including the strain rate effects and a Generalised Incremental Stress State dependent damage model (GISSMO) should be implemented in future works. 
Table 4. Comparison of cumulated crack lengths obtained from drop tower experiments and LS-DYNA simulations for various impact energies.

\begin{tabular}{lccc}
\hline \multirow{2}{*}{$\begin{array}{l}\text { Impact } \\
\text { Energy }\end{array}$} & \multicolumn{2}{c}{$\begin{array}{c}\text { Cumulated crack length } \\
(\mathbf{m m})\end{array}$} & Difference (\%) \\
\cline { 2 - 3 } & Experiment & LS-DYNA & \\
\hline $3 \mathrm{~J}$ & 34.67 & 30.29 & 12.63 \\
\hline $6 \mathrm{~J}$ & 44.53 & 49.19 & 10.46 \\
\hline $9 \mathrm{~J}$ & 66.67 & 60.29 & 9.57 \\
\hline $12 \mathrm{~J}$ & 67.48 & 69.8 & 3.44
\end{tabular}

\section{Conclusions}

An original method combining impact tests, high speed imaging and FE modelling was developed to characterize and predict the impact behaviour of composite samples subjected to low velocity impact. PPhemp fibres (PP-H) and PP-glass fibres (PP-G) composites were manufactured with the same volume fraction (12 vol\%) and their respective impact behaviour were compared. It was found that although PP-G composites could withstand higher impact loads, PP-H biocomposite exhibited a higher deformation at break leading to a significantly higher absorbed energy until breakage for any impact energy. This phenomenon is believed to be due to differences in the fibre characteristics, i.e. lower stiffness and strain at break of hemp fibres, and failure mechanisms. SEM observations revealed that damage mechanisms of PP-H and PP-G composites is dominated by matrix failure and fibre pull-out.

The implementation of a high speed camera enabled a correlation between force-displacement history and macro-cracks propagation. Independently of the fibres used, all composites seemed to break once one of the propagating macro-cracks has reached the edge of the clamped sample. Image analysis also allowed measuring the cumulated crack length until breakage. It was found that despite having similar fracture growth patterns, the energy absorbed during crack propagation is significantly higher for PP-H biocomposite as compared to PP-G composite. The origin of this phenomenon should be searched in underlying differences related to the failure mechanisms that could be approached by increasing the magnification and/or the acquisition speed to analyse fine details of the crack propagation, in particular matrix crazing. Post-mortem analysis by CT scans could also help to analyse matrix crazing.

A numerical FE model of the impact behaviour of PP-H biocomposite was developed using LS-DYNA. A macroscopic non-linear material model was used to model the material behaviour and a strain based 
erosion criteria was used to model damage. The results of the FE model were compared in terms of the forcetime histories as well as the cumulated crack lengths with the experimental data. The model was able to simulate the initiation and propagation of the macro-cracks and the results are in good agreement with the experimental drop tower data. The developed model could be used to predict the impact response of large automotive components made of natural fibre reinforced composites with minimal computational cost.

\section{Acknowledgements}

The authors gratefully thank the ANRT French Association as well as the ADEME French Organization (convention $\mathrm{n}^{\circ} 1682 \mathrm{C} 0043$ ) for their financial supports. KRR, NLM and SC thanks the European Union's Horizon 2020 Programme (HERMES project, grant agreement $n^{\circ}$ 636520) for its funding. 


\section{References}

[1] Mohanty AK, Misra M, Drzal LT, Selke SE, Harte BR, Hinrichsen G. Natural fibres, biopolymers and biocomposites: an introduction. In: Mohanty AK, Misra M, Drzal LT, editors. Nat. fibres, Biopolym. biocomposites, Boca Raton: Taylor \& Francis; 2005.

[2] Bledzki A, Gassan J. Composites reinforced with cellulose based fibres. Prog Polym Sci 1999;24:221-74. doi:10.1016/S0079-6700(98)00018-5.

[3] Hepworth D., Hobson R., Bruce D., Farrent J. The use of unretted hemp fibre in composite manufacture. Compos Part A Appl Sci Manuf 2000;31:1279-83. doi:10.1016/S1359-835X(00)000981.

[4] Karus M, Kaup M. Natural fibres in the European automotive industry. J Ind Hemp 2002;7:117-29.

[5] Patel H, Ren G, Hogg PJ, Peijs T. Hemp fibre as alternative to glass fibre in sheet moulding compound. Part 2-impact properties. Plast Rubber Compos 2015;44:291-8. doi:10.1179/1743289815Y.0000000030.

[6] Scarponi C, Pizzinelli CS, Sánchez-Sáez S, Barbero E. Impact load behaviour of resin transfer moulding (RTM) hemp fibre composite laminates. J Biobased Mater Bioenergy 2009;3:298-310. doi:10.1166/jbmb.2009.1040.

[7] Santulli C. Mechanical and Impact Properties of Untreated Jute Fabric Reinforced Polyester Laminates Compared With Different E- Glass Fibre Reinforced Laminates. J Compos Mater 2000;9:177-88. doi:10.1515/SECM.2000.9.4.177.

[8] Santulli C, Janssen M, Jeronimidis G. Partial replacement of E-glass fibers with flax fibers in composites and effect on falling weight impact performance. J Mater Sci 2005;40:3581-5. doi:10.1007/s10853-005-2882-y.

[9] Santulli C, Caruso AP. A Comparative Study on Falling Weight Impact Properties of Jute / Epoxy and Hemp / Epoxy Laminates . Malaysian Polym J 2009;4:19-29.

[10] Caprino G, Lopresto V, Langella A, Leone C. Damage and energy absorption in GFRP laminates impacted at low-velocity: Indentation model. Procedia Eng 2011;10:2298-311. doi:10.1016/j.proeng.2011.04.380.

[11] Caprino G, Carrino L, Durante M, Langella A, Lopresto V. Low impact behaviour of hemp fibre 
reinforced epoxy composites. Compos Struct 2015;133:892-901.

doi:10.1016/j.compstruct.2015.08.029.

[12] Caprino G, Lopresto V, Langella A, Durante M. Irreversibly absorbed energy and damage in GFRP laminates impacted at low velocity. Compos Struct 2011;93:2853-60. doi:10.1016/j.compstruct.2011.05.019.

[13] Shahzad A. Comparison of tensile properties and impact damage tolerance of hemp and glass fiber composites. J Reinf Plast Compos 2011;30:1877-93. doi:10.1177/0731684411431123.

[14] Pickering KL, Efendy MGA, Le TM. A review of recent developments in natural fibre composites and their mechanical performance. Compos Part A Appl Sci Manuf 2015. doi:10.1016/j.compositesa.2015.08.038.

[15] Rana A., Mandal A, Bandyopadhyay S. Short jute fiber reinforced polypropylene composites: effect of compatibiliser, impact modifier and fiber loading. Compos Sci Technol 2003;63:801-6. doi:10.1016/S0266-3538(02)00267-1.

[16] Bledzki AK, Gassan J, Zhang W. Impact properties of natural fibre reinforced epoxy foams. J Cell Plast 1999:550-62.

[17] De Vasconcellos DS, Sarasini F, Touchard F, Chocinski-Arnault L, Pucci M, Santulli C, et al. Influence of low velocity impact on fatigue behaviour of woven hemp fibre reinforced epoxy composites. Compos Part B Eng 2014;66:46-57. doi:10.1016/j.compositesb.2014.04.025.

[18] Scarponi C, Sarasini F, Tirillò J, Lampani L, Valente T, Gaudenzi P. Low-velocity impact behaviour of hemp fibre reinforced bio-based epoxy laminates. Compos Part B Eng 2016;91:162-8. doi:10.1016/j.compositesb.2016.01.048.

[19] Daiyan H, Grytten F, Andreassen E, Osnes H, Lyngstad O V. Numerical simulation of low-velocity impact loading of a ductile polymeric material. Mater Des 2012;42:450-8. doi:http://dx.doi.org/10.1016/j.matdes.2012.06.020.

[20] May M, Nossek M, Petrinic N, Hiermaier S, Thoma K. Adaptive multi-scale modeling of high velocity impact on composite panels. Compos Part A Appl Sci Manuf 2014;58:56-64. doi:10.1016/j.compositesa.2013.11.015.

[21] Sliseris J, Yan L, Kasal B. Numerical modelling of flax short fibre reinforced and flax fibre fabric reinforced polymer composites. Compos Part B Eng 2016;89:143-54. 
doi:10.1016/j.compositesb.2015.11.038.

[22] Liebold C, Erhart A. Recent enhancements on short-fiber reinforced plastics modeling in LS-DYNA. 10th Eur LS-DYNA Conf 2015.

[23] Kebir H, Ayad R. A specific finite element procedure for the analysis of elastic behaviour of short fibre reinforced composites. The Projected Fibre approach. Compos Struct 2014;118:580-8. doi:10.1016/j.compstruct.2014.07.046.

[24] Nutini M, Vitali M. Simulating anisotropy with LS-DYNA in glass- reinforced, polypropylene-based components. LS-DYNA Forum 2010:1-12.

[25] Chethan DS, Venkatesh GS, Gunti RS, Vinod Kumar CS. Experimental and Numerical Modeling of Hemp-Polyester Composites. In: Pandey K., Ramakantha V., Chauhan S., Arun Kumar A. (eds) Wood is Good. 2017, Springer, Singapore. doi.org/10.1007/978-981-10-3115-1_30

[26] Sandberg H, Rydholm O. Evaluation of Material Models to Predict Material Failure in LS-DYNA. Master's Diss Solid Mech 2016.

[27] Hosseinzadeh R, Shokrieh MM, Lessard L. Damage behavior of fiber reinforced composite plates subjected to drop weight impacts. Compos Sci Technol 2006;66:61-8. doi:10.1016/j.compscitech.2005.05.025.

[28] Hallquist JO. LS-DYNA User’s Manual. Livermore Software Technology Corporation, 2017.

[29] Kontermann C, Almstedt H, Scholz A, Oechsner M. Notch Support for LCF-Loading: A Fracture Mechanics Approach. Procedia Struct Integr 2016;2:3125-34. doi:10.1016/j.prostr.2016.06.390.

[30] Wu G, Yang JM, Hahn HT. The impact properties and damage tolerance and of bi-directionally reinforced fiber metal laminates. J Mater Sci 2007;42:948-57. doi:10.1007/s10853-006-0014-y.

[31] González EV, Maimí P, Camanho PP, Turon A, Mayugo JA. Simulation of drop-weight impact and compression after impact tests on composite laminates. Compos Struct 2012;94:3364-78. doi:10.1016/J.COMPSTRUCT.2012.05.015.

[32] Beckermann GW, Pickering KL. Engineering and evaluation of hemp fibre reinforced polypropylene composites: Fibre treatment and matrix modification. Compos Part A Appl Sci Manuf 2008;39:97988. doi:10.1016/j.compositesa.2008.03.010.

[33] Duval A, Bourmaud A, Augier L, Baley C. Influence of the sampling area of the stem on the 
mechanical properties of hemp fibers. Mater Lett 2011;65:797-800.

doi:10.1016/J.MATLET.2010.11.053.

[34] Placet V. Characterization of the thermo-mechanical behaviour of Hemp fibres intended for the manufacturing of high performance composites. Compos Part A Appl Sci Manuf 2009;40:1111-8. doi:10.1016/J.COMPOSITESA.2009.04.031.

[35] Placet V, Trivaudey F, Cisse O, Gucheret-Retel V, Boubakar LM. Diameter dependence of the apparent tensile modulus of hemp fibres: A morphological, structural or ultrastructural effect? Compos Part A Appl Sci Manuf 2012;43:275-87. doi:10.1016/J.COMPOSITESA.2011.10.019.

[36] Beukers A, Van Hinte E. Lightness: The inevitable renaissance of minimum energy structures. 010 Publishers; 2005.

[37] Davis JR. Tensile testing. 2nd Editio. ASM international; 2004.

[38] Guillon D. Fibres de verre de renforcement. Technique de l'ingénieur 1995;A2110.

[39] Thio YS, Argon AS, Cohen RE. Role of interfacial adhesion strength on toughening polypropylene with rigid particles. Polymer (Guildf) 2004;45:3139-47. doi:10.1016/J.POLYMER.2004.02.064.

[40] Li Y, Pickering KL, Farrell RL. Determination of interfacial shear strength of white rot fungi treated hemp fibre reinforced polypropylene. Compos Sci Technol 2009;69:1165-71. doi:10.1016/j.compscitech.2009.02.018.

[41] Park JM, Quang ST, Hwang BS, DeVries KL. Interfacial evaluation of modified Jute and Hemp fibers/polypropylene (PP)-maleic anhydride polypropylene copolymers (PP-MAPP) composites using micromechanical technique and nondestructive acoustic emission. Compos Sci Technol 2006;66:2686-99. doi:10.1016/j.compscitech.2006.03.014.

[42] Gentles FL, Thomason JL. Investigation of Interfacial Strength Between Polyethylene Terephthalate Fibre and Maleic Anhyrdide Modified Polypropylene. Eur Conf Compos Mater 2012:24-8.

[43] Yang L, Thomason JL. Interface strength in glass fibre-polypropylene measured using the fibre pullout and microbond methods. Compos. Part A Appl. Sci. Manuf., vol. 41, 2010, p. 1077-83. doi:10.1016/j.compositesa.2009.10.005.

[44] Simeoli G, Acierno D, Meola C, Sorrentino L, Iannace S, Russo P. The role of interface strength on the low velocity impact behaviour of PP/glass fibre laminates. Compos Part B Eng 2014;62:88-96. doi:10.1016/j.compositesb.2014.02.018. 
[45] Sorrentino L, Simeoli G, Iannace S, Russo P. Mechanical performance optimization through interface strength gradation in PP/glass fibre reinforced composites. Compos Part B Eng 2015;76:201-8. doi:10.1016/j.compositesb.2015.02.026.

[46] Boccardi S, Meola C, Carlomagno GM, Sorrentino L, Simeoli G, Russo P. Effects of interface strength gradation on impact damage mechanisms in polypropylene/woven glass fabric composites. Compos Part B Eng 2016;90:179-87. doi:10.1016/j.compositesb.2015.12.004.

[47] George J, Ivens J, Verpoest I. Surface Modification to Improve the Impact Performance of Natural Fibre Composites. Proc. ICCM12, France: 1999.

[48] Oksman K, Mathew AP, Långström R, Nyström B, Joseph K. The influence of fibre microstructure on fibre breakage and mechanical properties of natural fibre reinforced polypropylene. Compos Sci Technol 2009;69:1847-53. doi:10.1016/j.compscitech.2009.03.020. 